\title{
VIOLÊNCIA, FRACASSO ESCOLAR E JUVENTUDE PERIFÉRICA: CONTRIBUIÇÕES DA PSICOLOGIA ESCOLAR PARA A FORMAÇÃO DOCENTE CONTINUADA
}

\author{
VIOLENCE, SCHOOL FAILURE AND PERIPHERAL YOUTH: CONTRIBUTIONS \\ FROM SCHOOL PSYCHOLOGY TO CONTINUING TEACHING TRAINING
}

\author{
Larissa Figueiredo Salmen Seixlack Bulhões ${ }^{1}$
}

\begin{abstract}
Resumo
Estudos sobre a história da Psicologia Escolar como campo de conhecimento no Brasil tem apontado descompassos teórico-práticos nas produções da área, gerados pelo distanciamento entre o/a psicólogo/a e a realidade concreta das instituições de ensino. Este cenário corrobora com a propagação da expectativa clínica e patologizante referente à atuação do/a psicólogo/a escolar. Portanto, as escolas solicitam a intervenção desse/a profissional esperando que as queixas referentes ao fracasso escolar, à indisciplina e à violência redundem em diagnósticos para os/as estudantes, isentando de responsabilidade a lógica excludente das instituições burguesas que condiciona as relações interpessoais. Por meio de um relato de intervenção, o presente artigo visa contribuir para a superação da perspectiva clínica e individualizante do trabalho do/a psicólogo/a escolar no contexto da formação docente continuada. A partir da demanda institucional, a intervenção em tela voltou-se para a temática das relações entre juventude, violência e fracasso escolar. Os desafios enfrentados gravitaram em torno da superação da expectativa diagnóstica da instituição e na desconstrução do padrão ideal de bom/boa aluno/a. O conteúdo formativo consistiu em: conhecer os/as estudantes para além dos muros da escola; adotar a realidade dos/as estudantes como ponto de partida da intervenção; trabalhar a cultura periférica dentro da escola; apoiar a organização coletiva como meio para transformações objetivas. Os resultados obtidos apontaram para a transformação das relações interpessoais entre os/as docentes e os/as alunos/as envolvidos/as, os/as quais conquistaram espaços de expressão da cultura periférica na instituição, bem como de representatividade dos interesses estudantis.
\end{abstract}

Palavras-chave: psicologia escolar; formação docente; protagonismo juvenil; violência de Estado.

\begin{abstract}
Studies on the history of School Psychology as a field of knowledge in Brazil have pointed out theoretical and practical mismatches in the area's productions, generated by the distance between the psychologist and the concrete reality of educational institutions. This scenario corroborates the spread of clinical and pathological expectations regarding the scolar

1 Doutora em educação, Universidade Federal de Lavras, Lavras, Minas Gerais, Brasil. Email: larissa.bulhoes@ufla.br.
\end{abstract}

Revista Devir Educação, Lavras, vol.4, n.1, p.139-154 jan./jun., 2020. 
psychologist's performance. Therefore, schools request the intervention of the psychologist, hoping that complaints regarding school failure, indiscipline and violence result in diagnoses for students, exempting from responsibility the exclusionary logic of bourgeois institutions that condition interpersonal relationships. Through an intervention report, this article aims to contribute to overcoming this medical and individualizing perspective of the school psychologist's work in the context of continuing teacher education. From the institutional demand, the intervention on screen turned to the theme of the relationships between youth, violence and school failure. The challenges faced gravitated around overcoming the diagnostic expectation of the institution and deconstructing the ideal standard of good student. The training content consisted of: getting to know students beyond the school walls; adopt the students' reality as the starting point of the intervention; work on the peripheral culture within the school; support collective organization as a means for objective transformations. The results obtained pointed to the transformation of the interpersonal relationships between the teachers and the students involved, who have conquered spaces for the expression of peripheral culture in the institution, as well as the representation of student interests.

Keywords: school psychology; teacher training; youth protagonism; state violence.

\section{Introdução}

Estudos sobre a configuração histórica da Psicologia Escolar como campo de conhecimento no Brasil têm apontado descompassos teórico-práticos nas produções da área, gerados pelo distanciamento entre o/a psicólogo/a e a realidade concreta das instituições de ensino (GUZZO et al., 2010; MOREIRA; GUZZO, 2014; MARINHO-ARAÚJO, 2015). Essas investigações constatam que tal distanciamento se dá primordialmente pela ausência de políticas públicas as quais respaldem o exercício do/a psicólogo/a no chão das escolas, o que redunda em produções alheias às reais problemáticas do campo educativo justamente por estarem apartadas da concretude do cotidiano escolar.

Este cenário corrobora com a propagação da expectativa clínica e patologizante referente à atuação do/a psicólogo/a frente às demandas das instituições de ensino. Neste sentido, as escolas solicitam a intervenção do/a psicólogo/a esperando que as queixas referentes ao fracasso escolar, à indisciplina, à violência - entre outras demandas atribuídas à psicologia - redundem em diagnósticos para os/as estudantes e/ou seus familiares e, por conseguinte, isentem de responsabilidade as relações interpessoais concretas permeadas pela lógica institucional (GUZZO, 2016). 
O presente relato de intervenção visa contribuir para a superação desta perspectiva clínica e individualizante do trabalho do/a psicólogo/a escolar. Para tanto, tem como tônica o entendimento de que a participação ativa deste/a profissional no espaço concreto das escolas configura-se no meio para a construção de intervenções críticas as quais transcendam as relações de opressão e discriminação historicamente reproduzidas nas instituições de ensino (MOREIRA; GUZZO, 2016; BULHÕES; MEIRA, 2016; MACHADO, 2014).

Para o desenvolvimento desta reflexão, teremos como referência concreta uma experiência interventiva situada em uma das frentes do estágio em psicologia da educação do curso de psicologia de uma instituição pública de ensino superior. A intervenção tratou-se de uma formação continuada para docentes de uma escola municipal localizada na periferia de uma cidade do interior do Estado de São Paulo e voltou-se para a temática das relações entre juventude, violência e fracasso escolar. Os desafios enfrentados gravitaram em torno da superação da expectativa diagnóstica da instituição e da desconstrução do padrão ideal de bom/boa aluno/a - o qual limita-se àqueles/as que atendem aos parâmetros aquisitivos, estéticos, sexuais e culturais da elite dominante, depreciando a identidade da juventude periférica que frequenta as escolas públicas.

Com o intuito de contextualizar o relato ora apresentado, a seguir discorreremos sobre a construção histórica a qual redundou na perspectiva clínica de atendimento às demandas de fracasso escolar. Em seguida, abordaremos a concepção crítica a qual serviu de fundamentação teórica para a intervenção em tela.

\section{Determinantes históricos da patologização dos fenômenos educativos}

A concepção hegemônica de fracasso escolar reproduz um processo recorrente na sociedade de classes o qual fragmenta e singulariza os fenômenos, ocultando sua origem histórica e social (MEIRA, 2011). Destarte, ao invés de se considerar a lógica excludente produtora do fracasso escolar - a qual envolve as relações de opressão e marginalização da população periférica, a tradição de descaso com o ensino público no Brasil, as hierarquias e burocracias que entravam a autonomia da gestão escolar, as práticas de ensino etc. -, individualiza-se o que é socialmente construído e, em última instância, a culpa recai sobre a criança e sua família, que são responsabilizadas pelas mazelas sociais inerentes ao funcionamento do modo de produção vigente (MEIRA, 2011; PATTO, 1999; MACHADO, 
1997).

Esse processo redunda no encaminhamento de estudantes para o atendimento psicológico, do qual se espera categorizações norteadas por referenciais arbitrários e normativos; destarte, propõe-se a determinar o que falta na criança e a diagnosticá-la a partir dos pressupostos patologizantes de distúrbio e anormalidade (MACHADO, 1997). Neste ínterim, cabe a nós, psicólogas e psicólogos, validarmos cientificamente a necessidade da classe dominante em ocultar as desigualdades sociais, atribuindo suas causas a supostas habilidades individuais presentes ou não nos sujeitos. Ou seja, tradicionalmente, espera-se de nossa prática a mensuração e classificação da capacidade cognitiva da criança tendo como parâmetro os tendenciosos critérios elitistas que determinam os conhecimentos que valem mais e que, portanto, devem ser dominados para que o/a estudante seja considerado/a apto/a e capaz (SOUZA, 2001).

Acima de tudo, faz-se importante compreendermos as origens desta expectativa com relação a nossa prática nas instituições de ensino, dado que o modelo clínico interventivo em psicologia escolar predominou como principal referência de atuação no Brasil até meados da década de 1980 (SOUZA, 1997). A partir de então, iniciou-se um movimento de crítica a esse modelo tradicional de prática da psicologia, à luz da compreensão de que as dificuldades escolares, sobretudo das crianças pobres que frequentam as escolas públicas, devem ser apreendidas em sua totalidade, como resultado da violência simbólica cotidiana nesses espaços, a qual se materializa nas práticas escolares discriminatórias e hostis (PATTO, 1999). Essa nova concepção representou um avanço significativo dado que, a partir dela, foram postas novas perspectivas em nossa atuação nas escolas, as quais se propõem a quebrar com o caráter historicamente excludente das instituições de ensino, exigindo novas formas de pensarmos o papel da psicologia escolar como aliada na luta contra as várias facetas da exclusão e discriminação que atingem a população periférica usuária da educação pública (MARINHO-ARAÚJO, 2015).

$\mathrm{Na}$ intervenção que será relatada, as possibilidades e limites da atuação crítica do/a profissional psicólogo/a revelaram a importância do posicionamento firme contra condutas preconceituosas e aviltantes, historicamente cristalizadas. Nesta empreitada três elementos se revelaram cruciais: conhecer os alunos e alunas para além dos muros da escola; oportunizar diferentes formas de expressão dos/das estudantes sobre sua própria realidade; propiciar meios para que os/as estudantes promovam transformações objetivas valendo-se da 
organização coletiva.

\section{A demanda inicial}

O projeto em tela foi realizado como uma das frentes do estágio em psicologia da educação do curso de psicologia de uma instituição pública de ensino superior. A intervenção envolveu uma turma de oitavo ano do Ensino Fundamental II e teve início a partir das demandas da instituição escolar envolvida, de acordo com a qual os/as estudantes da sala citada eram pessoas desinteressadas, indisciplinadas e violentas durante as aulas. Segundo o posicionamento da instituição, o grande problema da turma era o fato de ser composta por meninos e meninas envolvido/as em atividades ilícitas - tráfico de drogas e pequenos furtos -, o que os/as levava a desprezar as aprendizagens escolares e a influenciar os/as demais estudantes, os/as quais, segundo a fala dos/as docentes, reproduziam uma postura tida como negligente e indiferente às proposições de ensino.

Ainda segundo a demanda institucional, o resultado desta realidade era o fracasso escolar associado à violência em sala de aula. Essas considerações eram apoiadas no fato de que grande parte dos alunos e alunas ainda não estava alfabetizada, o que prejudicava o trabalho pedagógico em sala de aula; além disso asseverava-se que os episódios de agressão física e verbal contra colegas e de vandalismo contra o patrimônio escolar tornava-se cada vez mais frequente, o que levou a instituição a solicitar com urgência a organização de uma ação interventiva.

\section{Metodologia da intervenção}

A metodologia adotada pautou-se na organização de encontros de formação continuada do corpo docente, articulada com observações ativas em sala de aula e com a elaboração de projetos com a turma de oitavo ano em tela. A formação continuada abordou o tema juventude, violência e fracasso escolar, e se organizou em 18 encontros, realizados no contexto das Atividades de Trabalho Pedagógico Coletivo - ATPC.

Nesses encontros de estudo, priorizou-se a apreensão crítica da queixa apresentada pela instituição, no intuito de compreendê-la em suas múltiplas determinações. Concomitantemente, as discussões teóricas eram articuladas a práticas pedagógicas 
organizadas em quatro eixos, quais sejam: conhecer os/as estudantes para além dos muros da escola; adotar a realidade dos/as estudantes como ponto de partida da intervenção; trabalhar a cultura periférica dentro da escola; apoiar a organização coletiva como meio para transformações objetivas.

\section{Resultados e discussão}

Detalharemos a seguir os procedimentos adotados em cada um dos eixos do processo interventivo, com a ressalva de que todos se articularam e se determinaram mutuamente e de forma concomitante ao longo da intervenção.

\section{Conhecer os/as estudantes para além dos muros da escola}

As impressões dos/as docentes sobre os alunos e alunas da turma de oitavo ano, confirmaram a constatação de Mezzalira e Guzzo (2015), cuja pesquisa identificou a atitude de não-envolvimento das instituições de ensino frente aos problemas pessoais de seus alunos e alunas, pelo temor de não saberem lidar com a situação. De acordo com as autoras, este também se configura em um dos motivos recorrentes para o adoecimento psíquico docente, dado que os/as educadores/as se sentem vulneráveis e, na tentativa de se protegerem, abstémse de qualquer envolvimento com o problema.

Destarte, no estudo de caso em tela, a escola reproduzia o discurso político e midiático oficial o qual retrata de forma mecânica e simplista a população de baixa renda como agente da violência, confirmando o estereótipo preconceituoso que busca transformar a pobreza em sinônimo de delinquência e criminalidade. Sob o pretexto da guerra contra o crime, o Estado capitalista responsabiliza os segmentos marginalizados da população pela brutalidade intrínseca a sua própria lógica estrutural e justifica sua atuação truculenta nas comunidades periféricas por meio da opressão policial.

De acordo com o relatório final da CPI sobre o Assassinato de Jovens no Brasil (BRASIL, 2015), o homicídio revelou-se como a principal causa da morte de jovens negros, pobres e moradores da periferia dos centros urbanos do país. A taxa de homicídios entre jovens negros é quase quatro vezes a verificada entre os brancos e, de cada 10 pessoas mortas pela polícia, sete são negras (BRASIL, 2015). Estes dados revelam o estabelecimento do fenômeno do racismo institucional, no qual elege-se o perfil dos/as jovens negros/as e pobres como suspeito em potencial e os sujeita a constantes agressões e violações de seus direitos 
mais elementares.

Esta lógica imperava no cotidiano das meninas e meninos do oitavo ano alvo da intervenção, os/as quais, apesar de estigmatizados/as como violentos/as e agressivos/as por seus professores e professoras, eram, na verdade, vítimas cotidianas da negligência do Estado na garantia do exercício pleno de seus direitos, aliada à brutalidade do embate entre as atividades ilícitas e as forças policiais na comunidade em que moravam. Destarte, a fim de superar os estereótipos reproduzidos dentro da instituição de ensino, discutiu-se com o corpo docente sobre os determinantes históricos, sociais e econômicos que redundam na criminalização da pobreza, e sobre as consequências disso quando, nas escolas, as crianças de famílias pobres são estigmatizadas como violentas. Como resultado dessa discussão, buscouse conhecer o cotidiano e as relações interpessoais que estes alunos e alunas vivenciavam para além dos muros da escola - espaço até então concebido como perigoso e violento e evitado ao máximo por professores, professoras e membros da gestão de ensino.

Nesse ínterim, quebrou-se com a norma implícita da instituição de se relacionar com os/as estudantes apenas dentro da redoma escolar e foi proposto que eles e elas organizassem um passeio pela comunidade, o qual compreenderia visitas aos espaços que os/as estudantes mais frequentavam. Ao longo desta atividade, foram apresentadas as possibilidades de lazer às quais aqueles/as adolescentes tinham acesso - o riozinho ao lado do esgoto a céu aberto na beira do qual conversavam, ouviam rap e jogavam cartas; os terrenos baldios em que empinavam pipas; os pastos em que, apenas por diversão, montavam nos cavalos e cavalgavam até serem pegos/as e castigados/as pelo dono da propriedade; as bocas de fumo que frequentavam aos finais de semana.

Ficou claro que qualquer outra opção de lazer além das que nos foi apresentada estava fora de cogitação para esses meninos e meninas, dado que os parques, praças, shoppings e cinemas ficavam nos bairros ricos da cidade, distantes dali, o que dificultava o acesso pelo custo financeiro implicado na locomoção. Além disso, a repressão policial à população jovem e periférica era constante nessas áreas, o que os/as desencorajava a visitá-las por medo das abordagens coercitivas e agressões que poderiam sofrer. Estas dificuldades retratam a existência de um apartheid não declarado, o qual isola a população pobre da convivência social com as elites; em última instância, as ações truculentas do Estado contra a periferia visam garantir que esta convivência se limite à exploração da força de trabalho de uma classe pela outra. 


\section{Adotar a realidade dos e das estudantes como ponto de partida da intervenção}

A partir destes dados coletados, os quais evidenciaram a marginalização desses garotos e garotas, o corpo docente se organizou e, dentro da sala de aula, foi formado um grupo nomeado pelos alunos e alunas de "Rimando contra a maré". Neste grupo, por meio do trabalho com letras de músicas de rap escolhidas pela turma, organizavam-se discussões que problematizavam as relações interpessoais dentro e fora da escola, tangenciando a reflexão sobre as condições objetivas de vida da população periférica e os estereótipos e preconceitos que a rodeiam.

A crítica social contida nos raps redundou em discussões que possibilitaram novos níveis de apropriação e compreensão do real, empoderando e motivando os alunos e alunas a expressarem seus questionamentos sobre sua realidade e ressignificarem os padrões identitários de juventude de periferia. Com o auxílio do conteúdo crítico contido nas músicas, problematizamos o espaço em que eles/as viviam, despertando a atenção para os direitos violados pelo poder público, o qual marcava sua presença não para a proteção dos cidadãos e cidadãs como se argumenta no discurso oficial das autoridades políticas, mas para a repressão da comunidade periférica em favor de uma elite minoritária.

Os alunos e alunas relataram experiências pessoais que ilustraram as dificuldades da vida na periferia, tais como o descaso com a saúde, com o saneamento básico e com a segurança dos/as moradores/as; a vida difícil dos pais, mães e responsáveis, muitas vezes comprometidos/as com três jornadas de trabalho para manter a família; a procura em vão por oportunidades de trabalho; o peso do estigma de ser morador e moradora de favela nas entrevistas de emprego; a alternativa do envolvimento com o tráfico de drogas por conta das carências financeiras; o consumo de drogas muitas vezes associado à descrença no futuro; a saudade de pessoas queridas que foram presas, estavam desaparecidas ou foram mortas pelas forças policiais.

O debate sobre a violação dos direitos humanos mais elementares, no contexto da formação continuada e na sala de aula, remeteu à questão da liberdade de ir e vir, segurança e integridade física. Como exemplo da violação destes direitos, os/as estudantes relataram sobre a imposição de um toque de recolher velado na comunidade, que os deixava vulneráveis à agressões físicas caso circulassem sozinhos/as à noite; bem como sobre as constantes ameaças 
que impediam essas crianças e suas famílias de denunciar os abusos, por medo de represálias. Estes e outros relatos enfatizaram a condição de vulnerabilidade da população periférica, a qual tem no Estado o seu principal algoz e não dispõe de qualquer instância que a proteja efetivamente.

Desta atividade redundaram conteúdos de grande relevância os quais permitiram ao corpo docente conhecer aqueles/as adolescentes para além de uma perspectiva pejorativa e discriminatória. Professores/as de história, geografia e língua portuguesa organizaram discussões sistemáticas em sala de aula sobre a violência de Estado nas comunidades periféricas, com ampla participação dos alunos e alunas, de modo que foi proposto que o trabalho envolvesse também a criação de letras de rap por parte dos/as estudantes.

\section{Trabalhar a cultura periférica dentro da escola}

Takeiti e Vicentim (2019) apontam que, para a juventude periférica, a concepção de periferia transcende a mera referência geográfica e alcança o significado de um território de existência, o qual cotidianamente constrói e reconstrói identidades. Ainda de acordo com os autores, por meio da arte periférica, a qual envolve a música, a poesia, a dança, o desenho, etc., esses jovens dão visibilidade para a vida e "contribuem para a construção de espaços públicos nas periferias e favelas, privatizadas pelo tráfico e submetidas às violências e a todas as formas de vulnerabilidades" (TAKEITI E VICENTIM, 2019, p. 259).

As oficinas de letras de rap foram organizadas à luz dessas prerrogativas, de modo que por meio das composições, os alunos e alunas expressavam de forma elaborada os seus interesses, indagações e inquietudes referentes aos determinantes do modo de vida que levavam, como podemos observar nos trechos de raps reproduzidos a seguir:

Me chamam de delinqüente/Como se eu não fosse gente,/De perto não passo de um sobrevivente./A vida na bandidagem não é minha opção /Mas não me deram escolha nessa grande nação/Cansei de me esconder e de me envergonhar/Por ser uma pessoa que deixou de sonhar/Que depois de muito coice decidiu se expressar/Mas aí de cima é muito fácil me julgar/Ninguém vê a miséria do lado de cá (Trecho do rap Identidade bandida).

No trecho acima, elaborado por dois alunos e uma aluna membros do grupo, podemos observar que a crítica social contida nas letras dos raps trabalhados em sala de aula redundou 
em reflexões que possibilitaram novos níveis de apropriação dos determinantes políticos e sociais envolvidos nas escolhas feitas por esses/as adolescentes - escolhas as quais, quando apreendidas em sua imediaticidade, geram julgamentos e estereótipos aviltantes. Souza (2000, p. 82) assevera que os/as jovens das comunidades periféricas "não escolhem suas estratégias com a mesma liberdade com que um jovem de classe alta opta entre estudar medicina ou engenharia, o núcleo de cálculo racional envolvido tem mais a ver com o pólo da necessidade que com uma dimensão de liberdade”.

Ou seja, o grau de liberdade existente nas escolhas feitas pelos/as jovens em uma sociedade marcada pelas disparidades de classe depende das condições objetivas de vida de que dispõem. Portanto, as opções que se colocam como viáveis subordinam-se à dimensão que impera no cotidiano desses/as adolescentes - se a dimensão da satisfação de suas necessidades básicas de sobrevivência ou a da liberdade socioeconômica de poder escolher uma carreira, por exemplo.

Da mesma forma, Souza et al. (2015) afirmam que o Brasil é marcado por diversas configurações de juventude, delineadas por determinantes sociais, econômicos e culturais. Portanto, as autoras asseveram a necessidade de se superar o estigma da adolescência como um período naturalmente conturbado e, portanto, de se compreender a vulnerabilidade a que a juventude brasileira de periferia está exposta no contexto da escassez de políticas públicas que a protejam e resguardem.

No estudo de caso em tela, a violência objetiva e subjetiva do Estado contra esses/as jovens fica explícita na combinação explosiva das várias facetas de sua negligência. Retira-se dessas crianças todas as possibilidades de uma infância digna; emudece-se qualquer via de expressão, denúncia ou reivindicação; limita-se, pela coerção bruta, suas possibilidades de ocuparem espaços além dos periféricos, marginalizados e estigmatizados; rotula-se de violentas e indignas as escassas possibilidades de escolha que lhes sobram, na busca de caracterizá-las como reflexos de uma suposta má índole inerente à natureza de quem as trilha; por fim, responsabiliza-se o indivíduo pelo que foi socialmente provocado. Esta foi a discussão trazida pelos/as professores/as no contexto formativo, na qual apontou-se a importância de espaços em que os/as adolescentes pudessem refletir sobre a associação reducionista de sua identidade à delinquência, à vergonha e ao julgamento social.

Esta reflexão sobre o movimento multifacetado de construção da identidade foi levada para a sala de aula e trouxe importantes direcionamentos. A princípio, nas discussões 
realizadas, os/as estudantes reproduziam em suas falas os estereótipos da instituição referentes ao perfil daquela turma, referindo-se a si mesmos/as como pessoas bagunceiras, indisciplinadas e desinteressadas. Frente a isso, os/as professores/as apontaram a possibilidade de conceber a identidade da turma para além dos rótulos impostos, a princípio, pela escola; a partir de então, novas representações identitárias sobre o grupo apareceram, tais como divertido, engraçado, unido, crítico, questionador, revolucionário, de modo que se colocou em movimento a identidade cristalizada de maus alunos e más alunas que aqueles/as jovens carregavam.

Destarte, as discussões formativas buscaram desconstruir a concepção idealizada de bom aluno e boa aluna imperante nas instituições de ensino por meio do desvelamento dos interesses a que servem este ideal, considerado como inatingível por aqueles/as adolescentes justamente por pressupor a subserviência a ordens e regras sem sentido. Por conseguinte, foi desvelada a função de manutenção das relações sociais de opressão oculta nas concepções tradicionalmente submissas de aluno/a e turma ideais. Tal questionamento foi levado para a sala de aula e apropriado pelos/as estudantes, como podemos observar no trecho de rap a seguir, elaborado por três garotas e dois garotos do grupo:

Eu sou diferente,/Mas sou inteligente,/Aluno bom não é aluno quieto é aluno que usa mente/Eu quero descobrir, quero perguntar/Quando vai ser a minha vez de falar/Chega de promessa e de ilusão /A escola diz que sim, mas a vida me diz não/A gente quer mudança não somos mais criança/Queremos mais do que uma falsa esperança /A gente vai lutar, a gente vai conseguir/Mas para isso precisamos nos unir (Trecho do rap Escola e esmola).

Assim, por meio das discussões realizadas no contexto da formação continuada e transformadas em intervenções pedagógicas em sala de aula, a postura julgadora da instituição escolar foi substituída por ações que permitiram aos/às estudantes compreender e se expressar sobre as múltiplas determinações de sua realidade. Da mesma forma, a postura violenta dos/as estudantes deu lugar ao questionamento e à ressignificação do seu papel na instituição de ensino.

\section{Apoiar a organização coletiva como meio para transformações objetivas}

Frente às problemáticas levantadas nos encontros, o corpo docente buscou associar as 
reflexões alcançadas pelas composições dos alunos e alunas com transformações objetivas nas relações interpessoais dentro da escola. Para tanto, o grupo de alunos/as entendeu como necessária a conquista de um espaço de expressão democrática dos e das estudantes na escola, espaço este o qual, apesar de se configurar como um direito, não está garantido na prática das instituições públicas de ensino.

A princípio, buscou-se compreender o modo como aqueles/as jovens vivenciavam os conflitos cotidianos na instituição, levando em consideração a versão da equipe gestora e do corpo docente sobre os problemas enfrentados. Os/as estudantes colocaram a necessidade de um espaço que lhes garantisse voz na escola, relatando situações de conflito com gestores/as e docentes, as quais, em geral, eram respondidas de forma agressiva por parte dos alunos e alunas. A discussão sobre meios coletivos de resolver o problema redundou na formação de um grêmio estudantil representativo dos direitos e interesses dos alunos e alunas na escola. $\mathrm{O}$ grupo compôs uma comissão organizadora das eleições do grêmio que passou a atuar na instituição no semestre letivo seguinte.

Portanto, por meio das discussões formativas e da parceria entre docentes e estudantes, em pouco tempo, de marginalizado e estigmatizado, o grupo passou a ser visto como questionador e mobilizador de ações transformadoras dentro da escola $\mathrm{O}$ projeto das oficinas de rap passou a fazer parte do cotidiano escolar e, ao final do ano letivo, o grupo, juntamente com membros do corpo docente, organizou um festival aberto à comunidade em que foram apresentadas paródias de rap, danças, poesias marginais e teatros sobre suas vivências pessoais acerca do tema violência de Estado, drogas e periferia. Os moradores e moradoras da comunidade participaram em peso e expressaram seus pontos de vista. O relato das experiências dos e das participantes foi bastante tocante e abriu espaço para a discussão de formas coletivas de proteger a comunidade das ações abusivas do Estado.

\section{Conclusão}

Ao longo do processo interventivo, ficou evidente a importância de se garantir o espaço de atuação do/a psicólogo/a na realidade concreta das instituições de ensino. É por meio do acesso ao cotidiano escolar que a prática do/a psicólogo/a reúne as condições objetivas para apreender criticamente as demandas e mediar transformações nas relações interpessoais da instituição, superando a expectativa clínica referente a sua atuação e 
mediando formas democráticas e coletivas de resolução dos conflitos.

Neste interim, a articulação entre as reflexões teóricas alcançadas no processo formativo do corpo docente, as intervenções pedagógicas em sala de aula e as ações transformadoras na escola levaram a instituição a superar o estigma pejorativo atrelado aos/às estudantes; e, desta forma, a compreendê-los/as a partir dos determinantes históricos, sociais e políticos que fazem da periferia um espaço de luta, resistência e sacrifícios. A abertura de possibilidades para a expressão da cultura periférica e a discussão de temáticas esclarecedoras das múltiplas determinações que compõem a difícil realidade daqueles alunos e alunas gerou resultados que transformaram sua essência identitária, exatamente por propiciar situações de ensino em que suas potencialidades pudessem se manifestar. Ao longo deste processo também foram ressignificadas as relações interpessoais dos/as estudantes com o corpo docente e gestor, abrindo-se espaço para o diálogo e o respeito mútuo. Estas transformações redundaram do esforço de ambos os lados em desconstruir concepções prévias sobre o outro e em compreender as premissas históricas e sociais dos conflitos enfrentados no cotidiano escolar (MACHADO, 2014).

Os resultados alcançados remetem à conclusão de que a superação do fracasso, da violência e da indisciplina escolar implica transcendermos o abismo existente entre a sala de aula e a vivência objetiva dos/as estudantes que a frequentam. Ou seja, a resistência dos alunos e alunas em se submeterem às arbitrariedades valorativas e elitistas dos currículos que compõem as disciplinas escolares, - interpretada como expressão de indolência, descaso etc pelas instituições de ensino - é, muitas vezes, um sinal saudável de luta contra a dissolução de sua identidade etnicorracial, cultural e socioeconômica. Dentro da lógica excludente da sociedade de classes, a escola violenta simbolicamente seu público ao eleger os padrões aquisitivos, estéticos, sexuais e culturais da elite branca como normativos e ideais, deixando claro aos alunos e alunas provenientes da periferia, desde os primeiros anos de sua escolarização, que jamais atenderão às expectativas atribuídas ao modelo imperante de cidadãos e cidadãs realizados/as e bem sucedidos/as.

Destarte, a lição mais significativa no que se refere à atuação crítica da psicóloga e do psicólogo escolar, aprendida com cada um dos membros do grupo de alunos e alunas, é a de que é necessário sermos indisciplinados/as diante de ordens cuja função é coagir e dominar; sermos revoltados/as diante de relações interpessoais opressoras; sermos maus alunos e más alunas quando o modelo ideal de estudante pressupõe a submissão e o silêncio diante da 
barbárie. É necessário resistir com intransigência às cotidianas tentativas de desqualificar a juventude pobre e periférica e lutar para que as instituições de ensino contemplem a diversidade das comunidades que a frequentam.

Neste sentido, a escola pública só será capaz de superar seus próprios déficits quando, de fato, se popularizar, incorporando a pluralidade como possibilidade e democratizando suas práticas e conteúdos de ensino. Apenas respeitando e reconhecendo a riqueza subjetiva dos alunos e alunas que a frequentam é que esta instituição será capaz de oferecer subsídios para que eles e elas conheçam e valorizem sua própria história - não mais como um atestado de sucessivos fracassos individuais que frustram a expectativa dominante de cidadão e cidadã exemplar, mas em suas articulações com uma sociedade marcada por desigualdades históricas as quais devem ser combatidas por meio da luta coletiva organizada. E, conforme demonstra o relato ora apresentado, a atuação da psicologia escolar crítica tem muito a colaborar com este processo, por meio de intervenções formativas que problematizem a tradição excludente das instituições de ensino e possibilitem a conquista de espaços de expressão e diálogo entre os membros da comunidade escolar.

Finalizamos o presente relato com a reprodução do trecho de um rap elaborado por quatro alunas e três alunos, o qual ilustra claramente o movimento em que novos significados sociais aprendidos na escola possibilitaram a compreensão dos condicionantes envolvidos na trajetória de construção da identidade da juventude periférica, atrelada aos conceitos de luta e resistência.

Qual é que é truta, nunca ouviu falar? Você é pobre, não é nobre, vai ter mesmo que ralar/ vai usar rédea ser a comédia da honrada classe média/ vai vender badego no pelego pro playboy ter aconchego/e vai ver seu pai rodar na mão dos gambé, vai ver sua mãe sofrer desenganar sua fé/ vai ser a escória que padece na farda de glória/ que nos autos de resistência esconde sua essência/ mas no final vamos ver quem é que vai suar frio, quando a quebrada souber que o lápis é o seu fuzil (Trecho do rap Escreve aí).

\section{Referências bibliográficas}

BRASIL. Congresso Nacional. Comissão parlamentar de inquérito destinada a apurar as causas, razões, consequências, custos sociais e econômicos da violência, morte e desaparecimento de jovens negros e pobres no Brasil. Relatório final. Presidente: Reginaldo Lopes. Relatora: Rosangela Gomes. Brasília: Centro Gráfico do Senado Federal, 2015.

GUZZO, R. S. L. et al. Psicologia e Educação no Brasil: uma visão da história e 
possibilidades nessa relação. Psicologia: Teoria e Pesquisa, 26(spe), 131-141, 2010.

MACHADO, A. M. Avaliação psicológica: mudanças necessárias. In: Tanamachi, E. R.; Rocha, M. L.; Proença, M. P. R. (org.). Psicologia e Educação: desafios teóricometodológicos. São Paulo: Casa do Psicólogo, 2001. p. 143-167.

MACHADO, A. M. Exercer a postura crítica: desafios no estágio em Psicologia Escolar. Psicologia: Ciência e Profissão, 34(3), 761-773, 2014.

MARINHO-ARAÚJO (Org.) Psicologia Escolar: Novos cenários e contextos de pesquisa, formação e prática. Campinas, SP: Alínea, 2015. p. 93-114.

MEIRA, M. E. M. Incluir para continuar excluindo: a produção da exclusão na educação brasileira à luz da Psicologia Histórico-Cultural. In: Meira, M. E. M.; Facci, M. G. D.; Tuleski, S. C. (org.). A exclusão dos "incluídos": uma crítica da Psicologia da Educação à patologização e medicalização dos processos educativos. São Paulo: Casa do Psicólogo, 2011. p. 113-124.

MEZZALIRA, A. S. C.; GUZZO, R. S. L. The educator and violent situations experience by student: Coping strategies. Estudos de Psicologia (Campinas), 32(1), 37-47, 2015.

MOREIRA, A. G; GUZZO, R. S. L. O psicólogo na escola: Um trabalho invisível? In: Gerais: Revista Interinstitucional de Psicologia, 7 (1), jan-jun, 42-52, 2014.

MOREIRA, A. P. G.; GUZZO, R. S. L. Situação-limite e potência de ação: Atuação preventiva crítica em psicologia escolar. Estudos de Psicologia (Natal), 21(2), 204-215, 2016.

PATTO, M. H. S. A produção do fracasso escolar: histórias de submissão e rebeldia. São Paulo: Casa do psicólogo, 1999.

SOUZA, M. R.; SOUZA, C. R.; DE DAHER, C. M. S.; CALAIS, L. B. de;. Juventude e drogas: uma intervenção sob a perspectiva da Psicologia Social. Pesquisas e Práticas Psicossociais, 10(1), 66-78, 2015.

SOUZA, M. L. de. Revisitando a crítica ao mito da marginalidade: a população favelada do Rio de Janeiro em face do tráfico de drogas. In: G. ACSELRAD (org.), Avessos do Prazer: drogas, aids e direitos humanos. Rio de Janeiro: Fiocruz, 2000. p. 89-103.

SOUZA, M. P. R. A queixa escolar e o predomínio de uma visão de mundo. In: Souza, M. P. R.; Machado, A. M. (org.). Psicologia Escolar: em busca de novos rumos. São Paulo: Casa do Psicólogo, 1997. p. 19-37.

TAKEITI, B. A.; VICENTIN, M. C. G. Juventude(s) periférica(s) e subjetivações: narrativas de (re)existência juvenil em territórios culturais. Fractal, Rev. Psicol., Rio de Janeiro, v. 31, n. spe, p. 256-262, dez. 2019. 
Recebido em: 05/05/2020.

Aprovado em: 15/05/2020.

Revista Devir Educação, Lavras, vol.4, n.1, p.139-154 jan./jun., 2020. 